\title{
Factors Influencing Environmental Knowledge, Attitude and Participatory Behavior towards Land Degradation. The case of Injibara Secondary and Preparatory School, North-Western Ethiopia
}

\author{
Adugnaw Birhanu \\ Department of Geography and Environmental Studies, Debre Tabor University, Post Box No: 297, \\ Debre Tabor, Ethiopia
}

\begin{tabular}{|c|c|}
\hline Abstract & Article Information \\
\hline \multirow{7}{*}{$\begin{array}{l}\text { Environmental knowledge, attitude and participatory behavior as one of the components of } \\
\text { the environmental education have been investigated for many respects. The present study } \\
\text { investigates the influence of age, gender, academic stream, grade level and family } \\
\text { background on environmental knowledge, attitude and participatory behavior. A total of } 286 \\
\text { study participants take part in the study. They were assessed using the Likert scale for } \\
\text { environmental attitude and participatory behavior and multiple-choice for environmental } \\
\text { knowledge. In addition, to strengthen the data obtained through questionnaire, Focused } \\
\text { Group Discussions and interview were used and the data obtained analyzed using SPSS } \\
\text { version } 15.0 \text { for windows. Results of the study revealed that there is statistically significant } \\
\text { variation on overall environmental knowledge, attitude and participatory behavior across } \\
\text { study participants due to variation in age and grade level. Based on gender and academic } \\
\text { stream there is significant difference in environmental knowledge. On the other hand, there } \\
\text { is no significant difference in respondents' environmental knowledge, attitude and } \\
\text { participatory behavior based on their family economic variation. }\end{array}$} & $\begin{array}{l}\text { Article History: } \\
\text { Received : } 20-04-2013\end{array}$ \\
\hline & Revised : 19-06-2013 \\
\hline & Accepted : 23-06-2013 \\
\hline & Keywords: \\
\hline & \\
\hline & \\
\hline & $\begin{array}{l}{ }^{*} \text { Corresponding Author: } \\
\text { Adugnaw Birhanu } \\
\text { E-mail: } \\
\text { adugnawbirhanu@gmail.com }\end{array}$ \\
\hline
\end{tabular}

\section{INTRODUCTION}

Currently, environmental degradation has caused among other things; global warming, depletion of stratospheric ozone layer, pollution of sea and rivers, air pollution, acid rain and desertification (Aydin, 2010). It is predicted that if the present trend of economic growth and consumption pattern continues, the natural environment will be increasingly stressed. Among the full scale environmental emergencies recognized by United Nations Development Program (UNDP) are water supply, land degradation, tropical forest destruction and loss of diversity, urban air pollution, and global warming as a result of green house gas emissions (Ramlogan, 1997).

Environmental degradation varies across places in the world. Accordingly, in developed world the major environmental degradation mostly are pollution, toxic and other wastes, and loss of biodiversity which resulted from rapid urbanization and industrialization. However, the most common environmental degradation problem in developing countries is the degradation of land which mostly resulted from lack of structured sustainable agricultural and economic activity (Adams, 2001).

The state of the natural environment in Ethiopia is even worse and deserves urgent attention and mitigation than the global situation. Land degradation in its all forms has been the main environmental problems face in Ethiopia. Such environmental issues of the world and Ethiopia need change in knowledge, attitude and behavior that favors sustainability of the environment for future sustainability in all aspects. To bring this change, education is a key factor in which educational institutions need to increase their efforts to educate their students for a sustainable future. Teachers are most influential in educating children and teenagers who becomes the leader of tomorrow in protecting the environment which all organisms need it for their survival. Thus, teachers should demonstrate proenvironmental behavior and attitudes since they are responsible for educating their students effectively in their teaching up on their academic qualification. They should also have good knowledge about the environment and its relationships with organisms (Esa, 2010). 
Adugnaw Birhanu

According to Said et al. (2003) environmental problems are caused by the current patterns of production of industries, patterns of consumption and behavior of consumers. The shaping of knowledge, attitude and value, commitment and skill needed to preserve and protect the environment begins at the early age. Hence, educators play an influential role in developing new pattern of knowledge, attitude and behavior in individuals.

Accordingly, as stated in (Yavetz et al., 2009), en vironmentally literate person possess the values, attitudes and skills that enables conversion of knowledge into action to solve environmental problems. From this it can be inferred that developing environmental responsible knowledge, attitude and behavior is needed towards land degradation to reduce and tackle the problem in the world in general and Ethiopia in particular. This can be achieved through environmental education (UNESCO, 1980; Roth, 1992).

The active participation of the general public is a key factor in preventing \& solving the environmental problems of contemporary society (UNESCO, 1978). However, before designing effective formal and informal environmental education programmes to foster responsible environmental knowledge, attitude and participatory behavior, it is necessary to investigate the variables that are important in the development of the individual's responsible environmental knowledge, attitude and participatory behavior. In the late 60 s many studies had been done in the industrially advanced parts of the world, concentrating on issues relevant to their conditions. Hence, the researcher believes that it is important to study factors influencing environmental knowledge, attitude and participatory behavior towards land degradation which is the major environmental problem appear in Ethiopia. This study is aimed to assess factors influencing environmental knowledge, attitude and participatory behavior towards land degradation. Within the framework of this overall objective, the following question guided
Sci. Technol. Arts Res. J., April-June 2013, 2(2): 140-147

this study: Are there significant differences in environmental knowledge, attitude and participatory behavior towards land degradation based on age, gender, academic stream, grade level, and family background?

\section{MATERIALS AND METHODS}

A cross-sectional survey research design with quantitative and qualitative research methods is used in order to study whether similarities or differences exist in environmental knowledge, attitude and participatory behavior towards land degradation based on age, gender, academic stream, grade level, educational level and family background.

\section{Study Area}

The study was conducted at Injibara Secondary and Preparatory School. Injibara is situated in a predominantly mountainous location with an elevation of 2,560 meters above sea level. It is the administrative center of the Agew Awi Administrative Zone in the Amhara National Regional State. Injibara is located at $10^{\circ} 58^{\prime} 06 " \mathrm{~N}$ Latitude and $36^{\circ} 52^{\prime} 50^{\prime \prime} \mathrm{E}$ Longitude with a distance of 450 kilometers along the asphalt road Northwest of Addis Ababa.

\section{Participants}

The target population under study is divided in strata based on education level (secondary and preparatory students and teachers), academic stream (social science and natural science), grade level $(9,10,11$ and 12) and gender (male and female). The number of subjects selected from these different strata is proportional to the total number of subjects in each stratum except for teachers which are selected based on their accessibility or availability by using convenience purposive sampling. Accordingly, a total of 286 study participants which 234 are secondary and preparatory students and 52 are secondary and preparatory teachers participated in the study as shown in table 1.

Table 1: Distribution of Sampled Students and Teachers for the Study based on Grade Level, Gender, Academic Stream and Educational Level.

\begin{tabular}{|c|c|c|c|c|c|c|c|c|c|}
\hline \multirow{2}{*}{\multicolumn{2}{|c|}{ Grade level }} & \multicolumn{2}{|c|}{ Number of students } & \multicolumn{2}{|c|}{$\begin{array}{l}\text { Number of } \\
\text { teachers }\end{array}$} & \multicolumn{2}{|c|}{$\begin{array}{c}\text { Number of sampled } \\
\text { students based on their } \\
\text { Proportion }(0.067)\end{array}$} & \multicolumn{2}{|c|}{$\begin{array}{l}\text { Number of teachers } \\
\text { sampled based on } \\
\text { convenience }\end{array}$} \\
\hline & & Male & Female & Male & Female & Male & Female & Male & Female \\
\hline \multirow{3}{*}{$\begin{array}{l}\text { Grade } 9 \\
\text { Grade } 10\end{array}$} & & 642 & 653 & 38 & 6 & 43 & 44 & 6 & 6 \\
\hline & & 557 & 573 & 34 & 8 & 37 & 38 & 6 & 6 \\
\hline & NS & 203 & 119 & 13 & 4 & 14 & 8 & 4 & 3 \\
\hline Grade 11 & SS & 106 & 103 & 10 & 4 & 7 & 7 & 4 & 4 \\
\hline \multirow{2}{*}{ Grade 12} & NS & 252 & 103 & 12 & 3 & 17 & 7 & 4 & 3 \\
\hline & SS & $\begin{array}{c}93 \\
1853\end{array}$ & $\begin{array}{c}97 \\
1648\end{array}$ & $\begin{array}{c}11 \\
118\end{array}$ & $\begin{array}{c}4 \\
29\end{array}$ & $\begin{array}{c}6 \\
124\end{array}$ & $\begin{array}{c}6 \\
110\end{array}$ & $\begin{array}{c}4 \\
28\end{array}$ & $\begin{array}{c}2 \\
24\end{array}$ \\
\hline \multirow{2}{*}{\multicolumn{2}{|c|}{ TOTAL }} & \multicolumn{2}{|c|}{3501} & \multicolumn{2}{|c|}{147} & \multicolumn{2}{|c|}{234} & \multicolumn{2}{|c|}{52} \\
\hline & & & & & & & $(234+5$ & 286 & \\
\hline
\end{tabular}

Source: Injibara secondary and preparatory school record office, 2011 
Adugnaw Birhanu

\section{Instrument}

This study incorporated qualitative data from interviews, focused group discussions and openended questions to enrich the quantitative data obtained from multiple choice knowledge tests and attitude and behavior Likert scale items which are used as the main data gathering instrument in this study. Data collection instruments were piloted to check their internal consistency. In this respect, the instruments were given to professionals in the field to judge the content validity and revisions were made based on their comments and suggestions. Besides, the tests were distributed to thirty subjects; twenty grade twelve students and ten teachers of secondary and preparatory school. Moreover the analysis of the pilot data was made to examine the relevance of each item to answer the research question. The internal consistency of the scale was found to be $0.78,0.75$ and 0.76 respectively for knowledge, attitude and participatory behavior items using Cronbach's alpha.

\section{Data Collection and Analysis}

After collecting knowledge, attitude and behavior inventory questionnaire, the researcher conducted FGDs that contain 1 male and 1 female student from grade $9,10,11$ and 12 for 2 hours in two sessions (1 hour for each session) which are selected with the support of room teachers. Due to limited time to conduct other type of interview, the researcher interviewed eight teachers through structured interview.

The survey questionnaire knowledge test has four choices and the correct responses were assigned a score of one and incorrect responses as a score of zero. The lowest possible total score is zero and the highest total score is $26(26 \times 1)$ (Environmental knowledge test scored out of $26 \%$, but for the sake of comparison convenience it is changed to $100 \%$.) which is changed out of $100 \%$ for comparison convenience. Accordingly when the participants scored for instance 26,20 , and 15 it is scored as 100, 77 and 58 respectively.

To identify students' attitude concerning land degradation issues a standardized Likert type of scale was employed. Likert scale applies scales ranging from strongly agree to strongly disagree. There were 21 items presented to measure students' and teachers' attitude which some of the items forward definite favorableness while the remaining items forward definite unfavorableness. In assigning values to favorable items the scale were weighted going from strongly agree, agree, undecided, disagree, strongly disagree, having 5,4 , $3,2,1$ values respectively. But, in the case of unfavorable items these values were reversed in the scale strongly disagree, disagree, undecided, agree,
Sci. Technol. Arts Res. J., April-June 2013, 2(2): 140-147

strongly agree, having $5,4,3,2,1$ values respectively.

Twenty participatory behavior inventory items written on a five point Likert scale was used to measure students' and teachers' participatory behavior or willingness to reduce and tackle the problem of land degradation to improve the environment. The scale employs five point Likert scales, ranging from strongly agree to strongly disagree. In this scale some of items were worded to show positive values whereas others were worded to show negative value. For the positive items value was assigned $5,4,3,2$ and 1 for strongly agree, agree, undecided, disagree and strongly disagree and this value was reversed for negative value items.

To analyze and interpret data gathered from the questionnaires were tabulated, analyzed and interpreted by using SPSS version 15.0 for windows. In order to analyze the data, appropriate descriptive statistical tools such as percentage, frequency table, standard deviation, mean, and inferential statistics of t-test, One-way ANOVA were used. Mean and standard deviation as well as percentage and frequency table are used to investigate average scores with respect to the variables under investigation while T-test and Oneway ANOVA were used for comparison and analyzing significance of difference between the mean scores of the respondents.

Moreover, students' and teachers' environmental knowledge, attitude and participatory behavior towards land degradation which is obtained from open-ended questions, interviews and focused group discussions are analyzed thematically in a qualitative way.

\section{RESULTS AND DISCUSSION}

\section{The Effect of Age}

In comparing environmental knowledge based on age, the mean score for 18 and <18, 19-22, 23-25 and 26 and $>26$ age categories is $64.8,64.8,73.6$ and 77.1 respectively which shows difference between age categories. To check if such mean difference based on age is statistically significant, one-way ANOVA is employed as summarized in table 2. The ANOVA summary revealed that there is a statistically significant mean difference $(\mathrm{df}=3,282$; $\mathrm{F}=8.994 ; p<0.05)$ in environmental knowledge of respondents about land degradation issues due to their variation in age.

On the other hand, in comparing participants environmental attitude towards land degradation 
Adugnaw Birhanu

based on age, the mean attitude score of study participants are 78.7, 78.4, 83.6 and 92.6 for respondents aged 18 and <18, 19-22, $23-25$, and 26 and $>26$ respectively that shows difference between age categories in their environmental attitude. The ANOVA summary shown on table 2 also revealed that the existing difference in the mean attitude score of participants based on age was statistically significant $(\mathrm{df}=3,282 ; \mathrm{F}=26.819$; $p<0.05)$.

In the case of participatory behavior, study participants aged 18 and below 18, 19-22, 23-25, and 26 and $>26$ scored 75.2, 78.1, 83.6 and 87.8 respectively having difference between age categories. The ANOVA summary also revealed that the existing difference in the study participants environmental participatory behavior for resolution of environmental problems such as land degradation is statistically significant $(\mathrm{df}=3,282$; $\mathrm{F}=18.510 ; p<0.05)$.

Generally, based on the mean scores obtained between different age categories it is concluded that
Sci. Technol. Arts Res. J., April-June 2013, 2(2): 140-147

study participants aged twenty three and above are knowledgeable, have right attitude and environment friendly participatory behavior which help in solving and preventing environmental problems such as land degradation than those participants of the study who are young and below twenty-three. In other words this study revealed that older aged are wise than younger aged in their environmental knowledge, attitude and participatory behavior. The finding of this study is consistent with the findings of (Getaye, 2007; Olli, et al., 2001, Bogner and Britta, 2010) which reports adults outperformed youngsters in terms of environmental knowledge and participatory behavior. In terms of environmental attitude this study findings is pretty similar with the findings of (Feleke, 2010; Aminrad, et al., 2011; Kebede, 2010) which strengthened the conclusion that older age group respondents have more favorable attitude than younger age. But this study is not consistent with (Yilmaz, et al., 2004) that reports younger aged had more knowledge, attitude and behavior towards environmental issues than did older students.

Table 2: Summary of ANOVA for Environmental Knowledge, Attitude and Participatory Behavior about Land Degradation by Age across All Groups.

\begin{tabular}{clccccc}
\hline \multirow{2}{*}{ Variables } & \multicolumn{1}{c}{ Sources } & $\begin{array}{c}\text { Sum of } \\
\text { Squares }\end{array}$ & df & $\begin{array}{c}\text { Mean } \\
\text { Square }\end{array}$ & F & Sig. \\
\hline \multirow{2}{*}{ Knowledge } & Between Groups & 6716.774 & 3 & 2238.925 & 8.994 & .000 \\
& Within Groups & 70197.328 & 282 & 248.927 & & \\
& Total & 76914.101 & 285 & & & \\
\multirow{3}{*}{ Attitude } & Between Groups & 5724.182 & 3 & 1908.061 & 26.819 & .000 \\
& Within Groups & 20062.769 & 282 & 71.145 & & \\
& Total & 25786.951 & 285 & & & \\
Behavior & Between Groups & 3875.041 & 3 & 1291.680 & 18.510 & .000 \\
& Within Groups & 19678.455 & 282 & 69.782 & & \\
& Total & 23553.497 & 285 & & & \\
\hline
\end{tabular}

\section{The Effect of Gender}

As it can be seen from table 3, the mean scores of male and female respondents are 71.2 and 65.3 with standard deviation of 15.4 and 17.1 respectively. There is mean difference of $5.9,2.8$ and 2.7 for environmental knowledge, attitude and participatory behavior respectively between the means of the two gender groups. In order to find out whether there is a significant statistical difference between mean scores of male and female participants of the study in their knowledge, attitude and participatory behavior, a t-test was employed.

As table 3 displays, the result of t-test showed that there is statistically significant difference between males and females in their environmental knowledge $(\mathrm{df}=284 ; \mathrm{t}=3.049 ; \quad p<0.05)$. However, there is no statistically significant difference between males and females in their environmental attitude $(\mathrm{df}=284 ; \mathrm{t}=0.013 ; p>0.05)$ and participatory behavior $(\mathrm{df}=284, \mathrm{t}=0.011 ; p>0.05)$ towards land degradation problem and related environmental issues. This shows that males had better environmental knowledge than females while having similar attitude and participatory behavior towards the problem, causes, consequences and solution towards land degradation. This finding is consistent with the findings of Dalelo (2010) Getaye (2007), Bukuma (2010), Demilew (2007), Roberta (2009) and Bogner and Britta (2010), which indicate that males are knowledgeable than females in their environmental knowledge while it disconfirms the findings of Adams, (2003), Alibeli (2009), Grzegorz et al., (2006) and Moghadam and Ehrampoush, (2005) that showed females have higher levels of environmental concern and efficacy than men did. 
Adugnaw Birhanu

On the other hand, in terms of environmental attitude and participatory behavior the study finding is similar with that of the findings of (Feleke, 2010; Kebede, 2010) who reports that there is no difference in students environmental attitude and
Sci. Technol. Arts Res. J., April-June 2013, 2(2): 140-147

participatory behavior based on their gender. Nevertheless, this study fails to consistent with the findings of (Pilgrim, et al., 2007) that reports there is no difference in eco-literacy levels among males and females.

Table 3: Result of T-Test for Environmental Knowledge, Attitude and Participatory Behavior about Land Degradation based on Gender across all groups.

\begin{tabular}{llccccccc}
\hline Variables & Gender & $\mathbf{N}$ & Mean & $\begin{array}{c}\text { Standard } \\
\text { deviation }\end{array}$ & df & $\begin{array}{c}\text { Mean } \\
\text { difference }\end{array}$ & t & Sig. \\
\hline Knowledge & Male & 152 & 71.17 & 15.436 & 284 & 5.850 & 3.049 & .003 \\
& Female & 134 & 65.32 & 17.014 & & & & \\
Attitude & Male & 152 & 82.7105 & 9.15404 & 284 & 2.78515 & 2.493 & .013 \\
& Female & 134 & 79.9254 & 9.72604 & & & & \\
\multirow{2}{*}{ Behavior } & Male & 152 & 80.7697 & 8.43320 & 284 & 2.71750 & 2.547 & .011 \\
\hline
\end{tabular}

\section{The Effect of Grade Level}

Grade 10 participants of the study with mean and standard deviation of 71.9 and 14.7 respectively outscored grade 9 participants having corresponding figures of 63.8 and 15.8 in their environmental knowledge test from secondary school level. In similar way from preparatory grade level, grade 12 research participants with mean and standard deviation of 73.1 and 13.6 respectively out scored grade 11 participants having corresponding figures of 66.9 and 20.3 in their environmental knowledge. In order to find out whether there is a significant statistical difference between the participants of grade9, grade 10, grade 11 and grade 12 mean scores in their environmental knowledge about land degradation, one-way ANOVA is employed. The ANOVA summary as it is illustrated in table 4 revealed that the existing difference in the participants environmental knowledge about environmental problems such as land degradation is statistically significant $(\mathrm{df}=3$, $282, \mathrm{~F}=5.644, p<0.05)$.

As depicted in table 4, similar to environmental knowledge, grade 10 participants with mean and standard deviation of 82.9 and 7.8 respectively outscored grade 9 participants having corresponding figures of 78.9 and 10.5 in their environmental attitude test from secondary school level. And from preparatory grade level, grade 12 research participants with mean and standard deviation of 84.2 and 8.6 respectively out scored grade 11 participants having corresponding figures of 81 and 10.1 in their environmental attitude. Similar to environmental knowledge as it is displayed in table 6, for environmental attitude mean score comparison one-way ANOVA is employed and show statistically significant difference $(\mathrm{df}=3,282$; $\mathrm{F}=0.004 ; p<0.05$ ) in environmental attitude of study participants resulted from variation in grade levels they learn and teach.
As shown in Table 4, grade 10 participants of the study with mean and standard deviation of 78.7 and 9.1 respectively outscored grade 9 participants having corresponding figures of 77.6 and 10.2 in their environment friendly participatory behavior from secondary school level. In similar way from preparatory grade level, grade 12 research participants with mean and standard deviation of 82.5 and 7.3 respectively out scored grade 11 participants having corresponding figures of 81.6 and 7.3 in their environmental participatory behavior. In order to find out whether there is a significant statistical difference between the participants of grade 9, grade 10, grade 11 and grade 12 mean scores in their environmental participatory behavior about land degradation based on grade level, one-way ANOVA is employed and the summary of ANOVA in table 4 shows a statistically significant difference $(\mathrm{df}=3, \quad 282$; $\mathrm{F}=0.004 ; p<0.05$ ) among the participants of the study as a result of variation in grade levels they learn and teach.

From the above results, it is clear that grade ten and twelve participants of the study are better in their environmental knowledge and attitude. But in terms of environmental participatory behavior grade eleven and twelve shows better participatory behavior. From this one can conclude that study participants who learn and teach in high grade level are more environmentally knowledgeable and have better environmental attitude and participatory behavior than those from lower grade level learners and teachers. This may be due to, as their grade level increases their exposures for different concepts of environmental issues as well as their thinking ability also increases which finally develop strong sense of participatory behavior in environment friendly activities. This study finding is not consistent with the findings of (Kebede, 2010) 
Adugnaw Birhanu

which reports that as level of education increases there is no change in level of environmental knowledge and attitude. But it is consistent with the
Sci. Technol. Arts Res. J., April-June 2013, 2(2): 140-147

findings of (Aminrad, et al. 2011) which reports as level of education increases there is corresponding increase in environmental awareness \& knowledge.

Table 4: Summary of ANOVA for Environmental Knowledge, Attitude and Participatory Behavior about Land Degradation based on grade level across all groups.

\begin{tabular}{clccccc}
\hline Variables & \multicolumn{1}{c}{ Sources } & $\begin{array}{c}\text { Sum of } \\
\text { Squares }\end{array}$ & df & $\begin{array}{c}\text { Mean } \\
\text { Square }\end{array}$ & F & Sig. \\
\hline \multirow{2}{*}{ Knowledge } & Between Groups & 4356.246 & 3 & 1452.082 & 5.644 & .001 \\
& Within Groups & 72557.855 & 282 & 257.297 & & \\
& Total & 76914.101 & 285 & & & \\
\multirow{4}{*}{ Attitude } & Between Groups & 1195.040 & 3 & 398.347 & 4.568 & .004 \\
& Within Groups & 24591.911 & 282 & 87.205 & & \\
& Total & 25786.951 & 285 & & & \\
Behavior & Between Groups & 1091.736 & 3 & 363.912 & 4.569 & .004 \\
& Within Groups & 22461.760 & 282 & 79.652 & & \\
& Total & 23553.497 & 285 & & & \\
\hline
\end{tabular}

\section{The Effect of Academic Stream}

Table 5 revealed that the mean score of social science participants in the environmental knowledge test is 76.5 with a standard deviation of 8.9 while natural science participants mean score and standard deviation is 67.9 and 19.4 respectively. The independent sample t-test also shows the existing difference in the mean score of the two academic streams is statistically significant $(\mathrm{df}=122$; $\mathrm{t}=2.955 ; p<0.05)$ as a result of their difference in academic background. On the other hand as table 5 displays the mean score of social science study participants environmental attitude and participatory behavior is 84.2 and 82.9 respectively which revealed that the result did not indicate statistically significant differences for their attitude $(\mathrm{df}=122$; $\mathrm{t}=-$ $0.270 ; p>0.05)$ and participatory behavior $(\mathrm{df}=122$; $\mathrm{t}=-0.314 ; p>0.05)$ as a result of their academic stream background.

Thus, from this it is conclude that those who learn and teach social science subjects are more knowledgeable than those who are natural science background which strengthened the findings of (Kebede, 2010) which reports students from social science background are more knowledgeable than those from natural science background students.

On the other hand, in terms of environmental attitude there is no difference between those who are natural science and social science academic stream. This result is similar with (Bukuma, 2010) which indicates that there is no difference in environmental attitude towards land degradation between students who are natural and social science students. Similar to that of environmental attitude, there is no difference between social and natural science study participants in their environment friendly participatory behavior towards land degradation which contradicts with the findings of (Bukuma, 2010; Kebede, 2010; Dalelo, 2010) that reports natural science students have better participatory behavior towards land degradation.

Table 5: Result of T-Test for Students' and teachers' Environmental Knowledge, Attitude and Participatory Behavior about Land Degradation based on Academic Stream across All Groups.

\begin{tabular}{|c|c|c|c|c|c|c|c|c|}
\hline Variables & Stream & $\mathbf{N}$ & Mean & $\begin{array}{l}\text { Standard } \\
\text { deviation }\end{array}$ & df & $\begin{array}{l}\text { Mean } \\
\text { difference }\end{array}$ & $\mathbf{t}$ & Sig. \\
\hline \multirow{2}{*}{ Knowledge } & Social science & 51 & 76.51 & 8.990 & \multirow{2}{*}{122} & \multirow{2}{*}{8.606} & \multirow{2}{*}{2.955} & \multirow{2}{*}{.004} \\
\hline & Natural science & 73 & 67.90 & 19.374 & & & & \\
\hline \multirow{2}{*}{ Attitude } & Social science & 51 & 84.2157 & 10.07832 & \multirow{2}{*}{122} & \multirow{2}{*}{-.48294} & \multirow{2}{*}{-.270} & \multirow{2}{*}{.788} \\
\hline & Natural science & 73 & 84.6986 & 9.62446 & & & & \\
\hline \multirow{2}{*}{ Behavior } & Social science & 51 & 82.9020 & 7.33827 & \multirow{2}{*}{122} & \multirow{2}{*}{-.44050} & \multirow{2}{*}{-.314} & \multirow{2}{*}{.754} \\
\hline & Natural science & 73 & 83.3425 & 7.91837 & & & & \\
\hline
\end{tabular}


Adugnaw Birhanu

\section{The Effect of Family Economic Status}

In comparing the environmental knowledge based on study participants' family economic background, the mean score for study participants from poor, medium and rich families are 68.55, 67.83 and 69.62 respectively. As summary of ANOVA shown in table 6 , family economic background do not show statistically significant difference on their environmental knowledge $(\mathrm{df}=2$, 283; $F=0.260 ; p>0.05)$.
Sci. Technol. Arts Res. J., April-June 2013, 2(2): 140-147

In comparing participants environmental attitude towards land degradation based on families economic status, the mean attitude score of study participants are $81.6,80.9$, and 82.3 for study respondents from poor, medium and rich families respectively. The ANOVA summary shown in table 6 , revealed that the existing difference in the mean attitude score of participants based on their families economic background is not statistically significant $(\mathrm{df}=2,283 ; \mathrm{F}=0.531 ; p>0.05)$.

Table 6: Summary of ANOVA for environmental knowledge, attitude and participatory behavior on land degradation based on family economic background across all groups.

\begin{tabular}{lllllll}
\hline \multicolumn{1}{c}{ Variables } & \multicolumn{1}{c}{ Sources } & $\begin{array}{c}\text { Sum of } \\
\text { Squares }\end{array}$ & df & $\begin{array}{c}\text { Mean } \\
\text { Square }\end{array}$ & F & Sig. \\
\hline \multirow{2}{*}{ Knowledge } & Between Groups & 141.024 & 2 & 70.512 & .260 & .771 \\
& Within Groups & 76773.077 & 283 & 271.283 & & \\
& Total & 76914.101 & 285 & & & \\
& Between Groups & 96.388 & 2 & 48.194 & .531 & .589 \\
Attitude & Within Groups & 25690.563 & 283 & 90.779 & & \\
& Total & 25786.951 & 285 & & & \\
\multirow{3}{*}{ Behavior } & Between Groups & 455.958 & 2 & 227.979 & 2.793 & .063 \\
& Within Groups & 23097.539 & 283 & 81.617 & & \\
& Total & 23553.497 & 285 & & & \\
\hline
\end{tabular}

Finally, study participants environmental participatory behavior is compared based on their families economic status, the mean participatory behavior of study participants is $81.5,78.7$ and 78.7 for study participants from poor, medium and rich families respectively. The ANOVA summary shown in table 6 , revealed that the existing difference in mean participatory behavior score of study participants is not statistically significant $(\mathrm{df}=2,283$; $\mathrm{F}=2.793 ; p>0.05$ ) as a result of their families difference in level of economic status.

From the above analysis, it is concluded that there is no difference in environmental knowledge, attitude and participatory behavior due to family back ground in terms of economic status. This finding is not consistent with the findings of (Lyons and Break, 1994 and De La Vega, 2004) which shows that learners from higher/rich socio-economic family backgrounds were found to be more environmentally concerned than learners from lower/poor socio-economic backgrounds.

\section{CONCLUSION}

In line with the summary of findings the study showed significant differences in environmental knowledge, attitude and participatory behavior towards land degradation as a result of variation in age and grade level they learn and teach. Thus, it is concluded that older age groups are better in their environmental knowledge, attitude and participatory behavior than younger age groups. Respondents who learn and teach in lower graders are better in environmental knowledge while having lower environmental attitude and participatory behavior towards cause, consequence and possible solution for land degradation than the respondents who learn and teach in higher graders.

The study also showed significant differences in respondents' environmental knowledge while showing insignificant differences in their environment friendly attitude and participatory behavior towards land degradation due to their difference in their gender and academic stream. Hence, males and those who learn and teach social science academic subjects are more knowledgeable towards the cause, consequence and possible solution for land degradation than females and those who learn and teach natural science academic subjects. On the other hand, respondents from poor, medium and rich family have insignificant variations in their environment friendly knowledge, attitude and participatory behavior towards the cause, consequence and possible solution for land degradation.

\section{ACKNOWLEDGMENTS}

First and foremost, I would like to thank Dr. Tesfaye Sheferaw and Dr. Kidanemariyam Paulos for their efforts in providing me relevant advice, critical comments and constructive suggestions and 
Adugnaw Birhanu

encouragements throughout the study is conducted. The author would also thank Addis Ababa University for its financial support to conduct the study. And finally, I would like to thank my colleagues of Debre Tabor University who help me in editing the article especially Wudneh, Baymot, Belay, Dessalew, Habtu and Mitiku.

\section{REFERENCES}

Adams, W. (2001). Green development: Environment and sustainability in the third world. Second edition, Routledge, New York.

Adams, W. (2003). Promoting Environmental Responsible Behavior: An Evaluation of the Global Learning and Observations to Benefit the Environment (globe) Program. Unpublished M.A Thesis: University of South Africa.

Aini Mat Said., Fakhru'l-Razi Ahmadun., Laily Hj. Paim., and Jariah Masud, (2003). Environmental concerns, knowledge, and practices gap among Malaysian teachers. International Journal of Sustainability in Higher Education 4(4): 305-313.

Alibeli, M.A. and Johnson, C. (2009). Environmental Concern: A Cross National Analysis. Journal of International and Cross Cultural Studies 3(1).

Aydin, F. (2010).Secondary School Students' Perceptions towards Global Warming: A Phenomenological Analysis. Scientific Research and Essay 5(12): 15661570.

Bela Yavetz., Daphne Goldman and Sara Pe'er (2009). Environmental Literacy of Pre-service Teachers in Israel: A Comparison between Students at the Onset and End of their Studies. Environmental Education Research 15(4): 393-415.

Bogner, F. and Britta, O. (2010). Gender, age and subject matter: impact on teachers' ecological values. Environmentalist 30(2): 111-122.

Bukuma, T. (2010). Knowledge, Attitude and Practices of Preparatory Students about Land Degradation: The case of Eastern Wollega zone of Oromia Regional state. Unpublished MA thesis: Addis Ababa University.

Dalelo, A. (1999). The State of the Environment in Ethiopia and the Introduction of Environmental Education. The International Journal of Environmental Education and Information 18(4): 295-308.

Dalelo, A. (2001). Natural Resource Degradation and famine in Ethiopia: Assessment of Students' awareness and view. Flensburg University, German.

DeLa Vega, E. (2004). Awareness, Knowledge, and Attitude about Environmental Education: Responses from Environmental Specialists, High School Instructors, Students, and Parents, unpublished $\mathrm{PhD}$ dissertation: University of Central Florida, Orlando.

Demilew, A. (2007). The contribution of environmental education in raising students' knowledge, attitude and practice in selected first cycle secondary schools. M.A Thesis, Addis Ababa University.

Esa, N. (2010). Environmental Knowledge, Attitude and Practices of Student Teachers. International Research in Geographical and Environmental Education 9(1):3950.
Sci. Technol. Arts Res. J., April-June 2013, 2(2): 140-147

Feleke, E. (2010). Students' Awareness, Attitude and Intension towards Urban Environmental Problems in Selected Preparatory Schools of Addis Ababa. Unpublished M.A Thesis: Addis Ababa University.

Getaye, A. (2007). Learners and Academic staffs' Environmental Knowledge, Attitude, Intension Behavior (The case of Adama University), Unpublished M.A Thesis, Addis Ababa University.

Kebede, B. (2010).Students' Awareness and Attitude towards Land Degradation and Deforestation. Unpublished M.A Thesis: Addis Ababa University.

Lyons, E. and Breakwell, D. (1994). Factors Predicting Environmental Concern and Indifferences in 13-16 Year Olds. Environment and Behavior 26(2): 223-238.

Małgorzata Grodziéska-Jurczak, Anna Stepska, Katarzyna Nieszporek and Grzegorz Bryda (2006). Perception of Environmental Problems among Preschool Children in Poland. International Research in Geographical \& Environmental Education 15(1):62-76.

Moghadam, B. and Ehrampoush, M. (2005). Survey of Knowledge, Attitude and Practice of Yazd University of Medical Sciences Students about Solid Wastes Disposal and Recycling. Iranian Journal of Environmental Health Science Engineering 2(2):26-30.

Olli, E., Gunnar Grendstad., Dag Wollebaek (2001). Correlates of Environmental Behaviors: Bringing Back Social Context. Environment and Behavior 33(3):181208.

Ozgul Yilmaz, William J. Boone and Hans O. Andersen (2004). Views of elementary \& middle school Turkish students toward environmental issues. International Journal of Science Education 26(12): 1527-1546.

Pilgrim, S., Smith, D., Pretty, J. (2007). Across-Regional Assessment of the Factors Affecting Eco-literacy: Implications for Policy and Practice, Ecological Applications. 17(6): 1742-1751.

Ramlogan, R. (1997). Environment and human health: a threat to all. Environmental Management and Health, 8 (2): 51-66.

Roberta, S. (2009). Indications of environmental literacy: Using a new survey instruments to measure awareness, knowledge, and attitude of university age students: lowa state university. Retrieved from http://www.iowadnr.gov/reap/fiels/literacy thesis.pdf.

Roth C.E. (1992). Environmental Literacy: its roots, evolution, and directions in the 1990s (Columbus, OH, ERIC/SMEAC Information Reference Center).

UNESCO, (1978). Intergovernmental Conference on Environmental Education. Organized by UNESCO in cooperation with UNEP, Tbilisi, USSR, 14-26 October 1977. Final Report .Paris: UNESCO.

UNESCO, (1980). Environmental Education In The Light Of the Tbilisi Conference (Paris, UNESCO).

Zarrintaj Aminrad., Sharifah Zarina Binti Sayed Zakaria., Abdul Samad (2011). Influence of Age and Level of Education on Environmental Awareness and Attitude. The Social Sciences 6(1):15-19. 